количеству серы в растительных маслах в отработанных газах двигателя практически отсутствуют оксиды серы. К положительным экологическим факторам можно отнести снижение выбросов в атмосферу оксида азота $\left(\mathrm{NO}_{x}\right)$, оксида углерода $(\mathrm{CO})$, несгоревших углеводородов $\left(\mathrm{CH}_{\mathrm{x}}\right)$ и сажи $(\mathrm{C})$. Но необходимо отметить, что использование топлива на растительной основе содержит в себе проблемы, связанные с подготовкой топлива, учета его физико-химических свойств, правильной эксплуатацией двигателя и использования пахотных земель для выращивания растительных масел. В статье представлены результаты экспериментальных исследований по определению эффективных показателей при работе на соевом масле дизельного двигателя 6ЧН 26/34 производства «Первомайськдизельмаш», входящий в состав стационарного дизель-генератора ДГА-900 мощностью 900 кВт. Указанный дизельный двигатель с неразделенной камерой сгорания типа «Гесельман», газотурбинным наддувом и промежуточным охлаждением наддувочного воздуха. Более вязкое соевое масло имеет лучшие свойства с смазки сопряженных пар и узлов двигателя, в результате увеличивается срок службы самого двигателя и топливного насоса высокого давления в среднем на $60 \%$. Но более вязкое соевое масло ухудшает смесеобразования, распыление и сгорание топлива. Пусковые качества двигателя также ухудшаются. Но при повышении температуры вязкость соевого масла резко уменьшается. Проанализированы причины, которые привели к появлению вышеупомянутых проблем. Кроме того, описаны особенности и преимущества когенерационной силовой установки, дает возможность получить на выходе две формы полезной энергии - тепловую и электрическую. Применение когенерации значительно повышает общий коэффициент полезного действия установки и предоставляет значительные возможности для эффективной утилизации тепла и достижения максимального экономического эффекта.

Ключевые слова: дизельный двигатель; силовая установка; соевое масло; топливная аппаратура; температура отработанных газов; максимальное давление.

\title{
USE OF VEGETABLE OIL AS A FUEL IN A MEDIUM SPEED DIESEL ENGINE
}

\section{O. Hrabovenko, S. Dotsenko, V. Nesterenko, I. Shvets}

While being highly fuel-efficient, diesel engines are defined by relatively high emissions, which have a negative impact on people and the environment. In the future, most European countries plan to abandon the use of diesel engines after 2030. One way to use this type of engines is to convert them to alternative fuels from renewable energy sources, such as vegetable oils (rapeseed, sunflower and soya bean oils). A significant advantage of vegetable oils is that when they hit the ground, they break down in a couple of weeks. Sulfur oxides are virtually absent due to the small amount of sulfur in vegetable oils in the engine exhaust gases. Other environmental factors include reduced emissions of nitrogen oxides $\mathrm{NO}_{\mathrm{x}}$, carbon monoxide CO, unburned hydrocarbons and carbon black C. However, it should be noted that the use of vegetable-based fuel involves problems related to fuel preparation, consideration of physical and chemical properties and proper engine operation and use of arable land for the cultivation of vegetable oils. The article presents the results of experimental studies to determine the effective performance of soybean oil, six cylinder, four-stroke supercharged diesel engine (26 - the diameter of the cylinder, $\mathrm{cm}$; 34 - the piston stroke, $\mathrm{cm}$ ) produced by "Pervomaiskdieselmash", which is a part of the stationary diesel generator (DGA-900) with the capacity of 900 $\mathrm{kW}$. This diesel engine is with an undivided combustion chamber ("Geselman" type), gas turbine supercharging and intermediate charge air cooling. Soybean oil is more viscous and has better lubrication properties of conjugated vapors and engine components, as a result, the lifespan of the engine and high-pressure fuel pump increases by an average of $60 \%$. However, more viscous soybean oil impairs fuel mixing, spraying and combustion. Starting qualities of the engine also deteriorate. On the other hand, as the temperature rises, the viscosity of soybean oil decreases sharply. The reasons which led to the emergence of the abovementioned problems have been analysed. In addition, the features and advantages of the cogeneration power plant have been described, which makes it possible to obtain two forms of useful energy at the output such as thermal and electric. The use of cogeneration significantly increases the overall efficiency of the plant; it provides significant opportunities for efficient heat utilization and achieving maximum economic effect.

Keywords: diesel engine; power plant; soybean oil; fuel equipment; exhaust gas temperature; maximum pressure.

\section{Д.В. Левченко}

\section{ВИБІР ТА ОБГРУНТУВАННЯ МАТЕМАТИЧНОГО ПЛАНУ 6-ТИ ФАКТОРНОГО ЕКСПЕРИМЕНТУ ПРИ ДОСЛІДЖЕННІ ПУСКОВИХ ЯКОСТЕЙ ДВЗ}

\begin{abstract}
Представлено практичне значення застосування багатофакторного регресійного аналізу в інженерній практиці як необхідного кроку на иляху вдосконалення і оптимізаџії складних систем та процесів. Актуалізовані мета та задачі оптимізації процесу пуску високообертового малолітражного дизеля. Подані особливості підготовки багатофакторного експерименту досліджуваного процесу на основі регресійного аналізу та теорї математичного планування експерименту. Визначені якісні параметри для оптимізації процесу холодного пуску дизеля: миттєве прискорення колінчастого вала $\mathrm{dn} / \mathrm{d} \tau$ в момент прокручування колінчастого вала зовнішнім джерелом енергіі, щзо близький до часу витраченого на пуск ДВЗ при оптимальних параметрах системи пуску та енергоємність пуску, яка є інтегральною характеристикою еквіваленту витраченої енергї за час прокручування колінчастого вала зовнішнім джерелом енергї. Досліджений вплив обраних 6-ти вагомих факторів на визначені параметри якості пуску дизеля. Обтрунтований вибір регресійного рівняння у вигляді повного квадратичного поліному для відтворення досліджуваних функиій оцінки якості проиесу пуску, виходячи із попереднього вивчення впливу деяких окремих факторів, щуо використані в дослідженні. Проведено аналіз пропозицій щзодо вибору раціонального плану шестифакторного експерименту для пошуку ко-
\end{abstract}


ефіцієнтів регресійного поліному другої степені. Подано обтрунтування рімення щзодо вибору плану, спираючись на вимоги експериментального стенду та умов організації дослідження, досвід попередників та статистичні критерії теорії математичного планування експериментів. Рімення про обраний план експерименту в більшій мірі відповідає вимогам запланованого експериментального дослідження. Точки плану визначені на багатомірному кубі із необхідності варіювання на трьох рівнях із рівномірним кроком всіх 6-ти факторів, щьо були визначені як впливові. За умов наявного лабораторного стенду поточні значення факторів еквівалентної температури холодного пуску, частоти прокручування колінчастого валу та максимальної температури свічок розжарювання мають дисперсію установки в різних точках плану, а характер впливу факторів на показник енергоємності завчасно невідомий. В якості раціонального плану експерименту для організації поточного дослідження обрано ортогональний центральний композиційний план Бокса-Уільсона, щзо побудований за рахунок додавання до повнофакторного плану нижчого порядку точок плану на осях факторного простору зі збереженням вимог ортогональності і симетричності плану.

Ключові слова: Математичне планування експерименту, багатофакторний експеримент, квадратичний поліном регресії, центральний композиційний план.

\section{Вступ}

При розробці алгоритму керування складною технічною системою, зокрема в сфері двигунобудування, завжди виникають задачі оптимізації параметрів систем відносно досліджуваної функції відгуку, що несе виключно практичний характер і вузьку сферу застосування. Перед дослідженням переважно виникає задача оптимізації якісного показника системи за рахунок впливу на нього вагомих контрольованих факторів, кількість яких із ростом складності задачі вимушено зростає. Визначення характеру взаємозв'язків між залежними параметрами системи традиційно представляється у вигляді регресійного рівняння або системи рівнянь, вагові коефіцієнти яких визначаються за результатами вибіркового експерименту.

Теорія математичного планування експерименту (МПЕ) $є$ виключним інструментом в подоланні проблем планування і теоретичної підготовки зваженого раціонального експерименту, що відповідатиме вимогам будь-якої технічної задачі, що формулює дослідник. Принципами МПЕ закладено, що визначальний вплив на рішення щодо обраних критеріїв оцінки моделі і плану експерименту виходить здебільшого із досвідченості дослідника та умов проведення самого експерименту.

Лабораторні випробування пускових характеристик дизеля є досить вибагливим видом випробувань 3 точки зору витрат часу, складності керування вагомими факторами впливу (такими як температура навколишнього середовища, частота прокручування колінчастого валу (КВ), умови сумішоутворення в циліндрі), а також визначення комплексних показників якості пуску, що є складними 3 точки зору прогнозування характеру взаємозв'язків із окремими керованими факторами в умовах нестаціонарних процесів.

Етап усвідомлення і постановки дослідної задачі $є$ найбільш важливим для отримання якісного i вагомого результату дослідження. Об'єктом поточного дослідження $є$ автомобільний малолітражний високообертовий дизель серії ДТ розробки ДП
«ХКБД», параметри якого можна знайти в [1]. Характеристика пуску автомобільного ДВЗ зумовлює важливу експлуатаційну характеристику готовності транспортного засобу, що особливо гостро стоїть для рятівної, пожежної та військової техніки. Оптимізація процесу пуску за різними показниками надійності, швидкості, економічності або екологічності чи їх комбінацією займає важливий етап доводки конструкції двигуна. Дослідження якісних та кількісних взаємозв'язків між ключовими впливовими факторами та показниками якості пуску, розробка і поширення методик оптимізації процесу пуску залишаються актуальними як для дослідних лабораторій, так і для виробників ДВЗ.

\section{Огляд тематичних досліджень}

Як вже було висвітлено в попередній роботі за цією темою [2] організація багатофакторного, а саме 6-ти факторного дослідження пуску, $є$ наступним кроком дослідження процесу ефективного пуску малолітражного високообертового дизеля із метою оцінки комплексного впливу низки найбільш вагомих факторів якості пуску дизеля із врахуванням їх взаємної дії.

Основні фактори впливу на процес пуску дизеля визначені при обробці значного досвіду попередників. Окремо варто виділити напрям дослідження оптимізації пускових якостей дизеля без використання спеціальних систем полегшення пуску, серед яких можна відзначити роботи [3-7]. Таким чином, для проведення екстремального експериментального дослідження було виділено 6 лінійно незалежних факторів: еквівалентна температура холодного пуску $\left(t_{\text {хп.екв, }}{ }^{\circ} \mathrm{C}\right)$, частота прокручування КВ стартером $\left(n, \mathrm{xB}^{-1}\right)$, циклова подача палива $\left(\mathrm{Q}_{\text {ц }}\right.$ мм $^{3} /$ цикл), кут випередження упорскування палива (Өвуп, град п.к.в.), температура свічок розжарювання $\left(t_{\mathrm{cp}},{ }^{\circ} \mathrm{C}\right)$, температура в об'ємі камери згоряння на момент пуску $\left(t_{\mathrm{k} 3},{ }^{\circ} \mathrm{C}\right)$.

В практиці проведення експериментальних науково-дослідних робіт 3 дослідження процесів в ДВ3 знайшли широке застосування методи регресійного аналізу, що також стали основою для роз- 
витку математичної теорії експерименту. Особливо важливими є статистичні методи планування екстремальних експериментів [8]. Проте, незважаючи на майже п'ятдесятирічну актуальність застосування, ці методи залишаються у незмінному вигляді. Розвиваються здебільшого лише методи вирішення задач оптимізації за рахунок адаптації під використання електронно-обчислювальної техніки для систем комп'ютерної математики, таких як MATLAB [9].

\section{Мета і задачі дослідження}

Метою даної роботи є удосконалення існуючих рішень щодо планування експериментального дослідження пускових якостей ДВЗ виходячи з поставленої для дослідження задачі і раціоналізації кроків її вирішення.

Задачами цієї роботи $є$ визначення певного вигляду регресійного рівняння, що відповідає задачі дослідження якості пуску ДВ3, та розробка методу пошуку його коефіцієнтів, включаючи обгрунтування вибору раціонального плану експерименту.

\section{регресії}

Обгрунтування вибору квадратичної моделі

Відповідно до задачі дослідження процесу пуску автомобільного ДВ3, необхідно сформулювати вигляд регресійного рівняння, що має описувати процес пуску та давати його якісну оцінку. Регресійна модель має бути багатофакторною і враховувати не лише вплив окремих факторів на функцію відгуку, а й характер відношень між самими факторами.

Для вирішення задачі оптимізації процесу пуску нами пропонуються два основних комплексні показника якості пуску, що відповідають умовам дослідження і характеризують напрямки підвищення надійності пуску та мінімізації витрат енергії на процес пуску ДВЗ:

1. Миттєве прискорення $\mathrm{KB} d n / d \tau$ в момент прокручування КВ зовнішнім джерелом енергії, що близький до часу витраченого на пуск ДВЗ при оптимальних параметрах системи пуску.

2. Показник енергоємності пуску, що представлений інтегральною характеристикою еквіваленту витраченої енергії за час прокручування КВ зовнішнім джерелом енергії.

Перший показник безпосередньо характеризує якість пуску і корелює із широко розповсюдженим показником - часом, витраченим на пуск ДВЗ. Необхідність такого показника в тому, що він дозволяє поєднати в одну групу досліди 3 різними наслідками, в тому числі без факту запуску на досліджуваному проміжку часу.

Виходячи 3 того, що запропонований показник якості пуску і традиційний показник часу, витраче- ного на пуск, є залежними, можна зробити висновок щодо впливу окремих факторів згідно попередніх досліджень. Так $3[4,7]$ видно, що принаймні один $з$ факторів, а саме кут випередження упорскування палива має екстремальне значення всередині діапазону варіювання фактору і гарантовано може бути оптимізований. Про ділянку функції близьку до екстремальної кажуть «майже стаціонарна» і на функцію відгуку сильно впливають квадратичні члени. Стосовно інших факторів завчасно невідомо про їх характер впливу на функцію відгуку всередині прийнятих діапазонів варіювання, проте є підстави припускати нелінійний характер залежності від фактору циклової подачі палива [4].

Виходячи $з$ того, що для планування експериментального дослідження першим кроком $\epsilon$ визначення вигляду регресійної залежності, статистичну оцінку адекватності якої неможливо дати без проведення власне наступного експериментального дослідження, на практиці прийнято спиратися на досвід попередників і велику кількість тематичних досліджень 3 цього напрямку. Традиційним рішенням щодо невідомої форми зв'язків між незалежними факторами і функцією відгуку є використання степеневого поліному регресії. В джерелі [8] вказано, що для опису «майже стаціонарної» області не вдається скористатись лінійною залежністю і згідно практичного досвіду запропоновано використовувати повний поліном другої степені, що дозволяє отримати адекватну модель.

Таким чином, для оцінки поверхні відгуку було сформульовано регресійне рівняння у вигляді повного квадратичного поліному, що має на меті апроксимацію закону пуску дизельного двигуна в залежності від прийнятих факторів впливу. Вигляд поліному представлений формулою (1).

$$
\eta=\beta_{\left(z=z_{0}\right)}+\sum_{i=1}^{n} \beta_{(z=z+1)} x_{i}+\left[\sum_{i=1}^{n} \sum_{j=1}^{n} \beta_{(z=z+1)} x_{i} x_{j}\right],
$$

де $\beta$ - невідомі коефіцієнти рівняння регресії, $x-$ залежні змінні рівняння регресії, $n$ - число лінійно незалежних факторів, $z_{0}=0$-індекс вільного члена поліному, $i, j-$ індекси залежних змінних.

Число членів поліному і, відповідно, невідомих коефіцієнтів для поліноміальних моделей другого порядку визначаються за виразом:

$$
N=(n+1) \frac{(n+2)}{2} .
$$

Для 6 факторів число невідомих коефіцієнтів складає 28. Пошук невідомих коефіцієнтів досліджуваного поліному отримують за допомогою «Методу найменших квадратів», спираючись на експериментальні дані. Кількість і розташування експериментальних точок мають в достатній мірі 
відтворювати вигляд поверхні відгуку досліджуваного показника пуску від обраних факторів.

При розв'язанні задачі припускаємо, що в поставленому експерименті виконуються умови класичного регресійного аналізу за теорією Гаусса Маркова для отримання оцінок коефіцієнтів моделі $y=\eta+e$ і можливості аналізу їх властивостей:

- у кожному досвіді математичне сподівання випадкової помилки $e_{i}$ дорівнює нулю $M\left[e_{i}\right]=0$, $i=1 . . \mathrm{N}$;

- у всіх дослідах дисперсія постійна і однакова. $D\left[e_{i}\right]=\sigma^{2}=$ const, $i=1 . . \mathrm{N}$;

- помилки в будь-яких двох дослідах незалежні. $\operatorname{cov}\left[e_{i}, e_{j}\right]=0$, де $i, j \in[1, \mathrm{~N}]$;

- помилка $e_{i}$ в кожному досліді має нормальний закон розподілу $e_{i} \sim \mathrm{N}(\mu, \sigma), i=1 . . \mathrm{N}$.

Використаний поліном 2-ї степені дозволить проводити оптимізацію за прийнятими параметрами, що характеризують якість пуску ДВЗ. Враховуючи нелінійність поліному регресії для пошуку локального екстремуму функції необхідно вирішувати задачу нелінійного математичного програмування при виконанні обмежень першого роду, що накладаються на область визначення функції в межах діапазонів досліджуваних факторів: $g_{j}\left(x_{1} \ldots x_{n}\right) \geq 0$, де $x_{i}, i=(1 \ldots k)$ - параметри; $k$ - кількість параметрів; $g_{j}, j=(1 \ldots s)$ - обмеження; $s-$ кількість обмежень.

Для вирішення задачі нелінійного математичного програмування планується використання функцій пакету Toolbox Optimization, що є розширенням потужної системи комп'ютерної математики MATLAB [9]. Так, наприклад, функція fmincon() дає можливість використовувати методи довірчих областей (Trust Region), активного набору (Active Set), послідовного квадратичного програмування або внутрішньої точки (Interior Point) для розв'язання задачі умовного нелінійного програмування.

Вибір і характеристика раціонального плану експерименту

Для пошуку невідомих коефіцієнтів регресійного рівняння необхідно експериментально дослідити область визначення функції відгуку, обмежену границями варіювання факторів, та отримати експериментальні точки на поверхні відгуку досліджуваного процесу. Цей етап здебільшого найскладніший, бо безпосередньо має визначати точку протистояння між статистичною точністю прийнятого плану і об'ємом експериментального дослідження.

Згідно робіт з теорії МПЕ для опису функції відгуку у вигляді регресійного поліному 2-ї степені в практичній реалізації інженерних задач знайшли найбільше поширення плани експериментів на кубі, більше того, в роботі [11] вказано, що використання ротатабельних ортогональних планів та планів із випадковим розкидом точок експерименту невигідно, при умові, що регресійна модель досить точно описує функцію відгуку.

Враховуючи багатофакторність задачі виникає потреба в зменшенні кількості експериментів відносно повнофакторного плану експерименту та оптимізацію плану за обраними статистичними критеріями. Зокрема оптимізація плану характеризується не лише статистичними критеріями, а i умовами проведення експерименту, що включають діапазони варіювання та складність керування змінними факторами. Для проведення дослідження пускових якостей дизеля при визначених факторах виникає проблема регулювання певних рівнів факторів, таких як еквівалентна температура холодного пуску, частота прокручування КВ від електростартеру та температура свічки розжарювання. Наприклад, при підготовці експерименту прийнятий керований фактор впливу на момент опору прокручуванню колінчастого валу стартером зумовлений обраним передаточним відношенням КЗП, що може приймати лише певні дискретні значення. Це накладає додаткову важливу умову на шуканий план експерименту і зумовлює його ортогональність $\left(\sum_{u=1}^{N} x_{i u} x_{j u}=0, i \neq j, i=(1 \ldots n), j=(1 \ldots \mathrm{n})\right) \quad$ i симетричність $\left(\sum_{u=1}^{N} x_{i u}=0, i=(1 \ldots n)\right)$.

Виходячи із теорії планування експерименту, як показано в [1] для розглядання повного поліному другої степені і оцінки кривизни поверхні відгуку необхідно включити в план експерименту точки $з$ проміжними значеннями факторів. Задля досягнення симетричності плану точки розташовуються на осях координат факторного простору в середині діапазонів варіювання факторів.

Для досягнення статистичних критеріїв якості плану, значення його факторів перетворені в нормовані згідно залежності (3) фактори, що будуть змінюватись на трьох рівнях прийматимуть значення -1, 0 і 1 відповідні мінімальному, середньому і максимальному значенню варіювання факторів.

$$
x_{\text {норм }}=\left(x-x_{\mathrm{н}}\right) / \Delta x,
$$

де $x-$ поточне значення фактору: $x_{\mathrm{H}}=\left(x_{\max }-x_{\min }\right) / 2-$ середина досліджуваного діапазону; $\Delta x$ - крок варіювання фактору.

Велике поширення в інженерній практиці при плануванні на кубі отримали D-оптимальні плани експериментів, які можна побудувати в тому числі 
для планів із різним числом варіювання факторів, не завжди дають достатню точність при раціональній кількості дослідів [11-13].

Традиційно для використання в підготовці технічного експерименту, націленого на опис складної регресійної моделі комплексного параметру, застосовуються ортогональні симетричні центральні композиційні плани (ЦКП) Бокса-Уільсона. $[10,11]$. Число точок в центральному композиційному плані Бокса-Уільсона знаходять за залежністю $N=2^{n}+2 n+1$ і для 6-ти факторної моделі $N=77$ точок експериментів. Згідно порівняльної характеристики, приведеної в [11], цей план не є оптимальним 3 точки зору кількості експериментів і статистичних параметрів, проте відомо, що порівняльна характеристика сформована за результатами досліду, вигляд функції відгуку якої попередньо відомий і обраний для оцінки точної моделі регреciï. Ортогональний ЦКП, побудований на основі повнофакторного плану експерименту 1-ї степені, має велику точність апроксимації в околі вузлових точок плану навіть у випадку відсутності квадратичної залежності досліджуваної функції від окремого фактору.

Широко поширене застосування ортогональних ЦКП, що базуються не на повнофакторному плані нижчого порядку, а на піврепліці повнофакторного плану при кількості факторів 5 і більше $[11,14]$. Таке рішення дало б змогу заощадити 32 точки плану без значної втрати точності апроксимації моделі.

Свідоме використання повнофакторної бази ЦКП замість піврепліки від повнофакторного плану при майже однакових характеристиках точності плану за [11] зумовлене досягненням високої стійкості до можливих похибок установки значень факторів в окремих точках дослідження за рахунок оцінки груп точок експериментів з близькими комбінаціями факторів.

Таким чином, ортогональний ЦКП БоксаУільсона відрізняється від більш компактних близьких до D-оптимальних планів хорошим співвідношенням статистичної точності і кількості експериментальних точок при значній надійності результату апроксимації. До того ж важливою особливістю ЦКП є наявність однієї центральної (нульової) точки. При проведенні експериментального дослідження можлива реплікація цієї точки в необмеженій кількості для аналізу точності вимірювальної схеми та визначеності відносно нормальної дисперсії установки відносно обраних значень факторів.

\section{Висновки}

1. Зроблено аналіз і надано якісну оцінку обраної таблиці 6-ти факторного плану експерименту, для пошуку вагових коефіцієнтів регресійного поліному, в якості моделі пуску ДВЗ.

2. Конкретизовані положення теорії математичного планування експерименту, а саме вибір та обгрунтування вигляду регресійної моделі у вигляді повного поліному 2-ї степені при виконанні задачі дослідження пускових якостей ДВ3.

3. Запропоновано два основних показника якості процесу пуску:

- миттєве прискорення КВ $d n / d \tau$ в момент прокручування КВ зовнішнім джерелом енергії, що близький до часу витраченого на пуск ДВЗ при оптимальних параметрах системи пуску;

- енергоємність пуску, яка $є$ інтегральною характеристикою еквіваленту витраченої енергії за час прокручування КВ зовнішнім джерелом енергії.

\section{Список літератури:}

1. Грицюк О.В. Теоретичні основи та практичні методи створення високообертового малолітражного дизеля багатоцільового призначення малолітражного дизеля : автореф. дис. ... д-ра техн. наук : 05.05 .03 / О. В. Грииююк. : Харків. НТУ «ХПІ». - Харків, 2010. - 47 с. 2. Левченко Д.В. Обгрунтування необхідності наступного кроку щодо застосування методу математичного планування експерименту у дослідженні ДВЗ / Д.В. Левченко, О.В. Грицюк, Кузьменко А.П. // Двигатели внутреннего сгорания. - 2019. - №2. - С. 66-71. 3. Кухаренок Г.М. Метод определения параметров топливоподачи $в$ дизелях на режиме пуска / Г.М. Кухаренок, А.Н. Марчук // Наука и техника. - 2011. - № 1. - C. 40-47. 4. Половинка Э. М. Исследование пусковых режимов судового высокооборотного Двигателя / Э.М. Половинка, Р.Я. Гарвалов, Д.С. Мазур, А.О. Рознатовский // Матеріали науково-технічної конферениії «Річковий та морський флот:експлуатація $i$ ремонт», 22.03.2018 23.03.2018.- Одеса : HУ "OMA", 2018. - C. 10-14. 5. Poбустов В.В. Системный анализ факторов влияния на yсnех пуска ДВС в условиях низких отрицательных температур / В.В. Робустов // Омский научный вестник. - 2006. - № 3 (36). - С. 100-104. 6. Маркин А.Г. Энергообеспечение пуска двигателя внутреннего сгорания автомобиля / А.Г. Маркин, Б.В. Журавский, А.П. Жигадло // Вестник Сибирской государственной автомобильно-дорожной академии. - 2015. - № 5 (45). C. 26-30. 7. Грицюк A. B. Опьт применнения метода планируемого эксперимента в исследованиях переходных процессов пуска дизельного двигателя / А.В. Грицюк // Двигатели внутреннего сгорания. - 2012. - № 2. - С. 5359. 8. Налимов В.В. Статистические методы планирования экстремальных экспериментов / В.В. Налимов, Н.А. Чернова. - М. : «Наука», 1967. - 340 с. 9. Гольдштейн А.Л. Оптимизачия в среде MATLAB: учебное пособие / А.Л. Гольдштейн. - Пермь: Изд-во Перм. наи. исслед. политехн. ун-та, 2015. - 192 с. 10. Методические указания по применению методов математического планиирования эксперимента в НИР студентов, в курсовом и дипломном проектировании ; под ред. : А.Э. Симсона. - Харьков : Харьковский институт инженеров жел.-дор. Транспорта им. С.М. Кирова, 1982. - 34 с. 11. Андрукович П. Ф., Планы второго порядка на гиперкубе, близкие по свойствам к D-оптимальным.- $B$ 
кн.: Новые идеи в планировании эксперимента / П.Ф. Андрукович, Т.И. Голикова, С.Г. Костина. - М. : Наука, 1969. - C. 140-153. 12. Антиль Ж. D-оптимальное планирование для полиномиальной регрессии: выбор степени и робастность / Ж. Антиль А. Л. Вайнберг-Алле //. Прикладная эконометрика. - М : РАНХіГС, 2007. №. 4 (8). - С. 65-66. 13. Лапач С.Н. Робастные планы эксперимента / С.Н. Лапач // Математичні машини $i$ системи. - 2016. - № 4. - С. 111-121. 14. Бродский В.3. Таблищь планов эксперимента. Для факторных и полиномиальных моделей. Справочное издание / В.3. Бродский, Л.И. Бродский, Т.И. Голикова, Е.П. Никитина и др. - Под ред. В.В. Налимова. - М.: Металлургия, 1982. $-753 c$

\section{Bibliography (transliterated):}

1. Grytsyuk, A.V. (2010), Theoretical foundations and practical meth-ods of creating a high-speed small-capacity diesel engine of multi-purpose: dissertation [Teoreticheskie osnovy i prakticheskie metody sozda-niya vysokooborotnogo malolitrazhnogo dizelya mnogocelevogo naznacheniya: dis. ... d-ra tehn. nauk], Kharkiv, NTU "KhPI", 430 p. 2. Levchenko, D.V., Gricjuk, A.V., Kuzmenko A.P. (2019), "Obhruntuvannya nastupnoho kroku shodo zasosuvannya method of mathematical planning experiment experiment dloshenni DVZ" [Obtruntuvannja neobhidnosti nastupnogo kroku shhodo zastosuvannja metodu matematichnogo planuvannja eksperimentu u doslidzhenni DVZ], Dvigateli vnutrennego sgoranija, №2, p.p. 6672. 3. Kukharenok G.M. Marchuk A.N. (2011), "Method for determining fuel supply parameters in diesel engines at start-up mode" [Metod opredeleniya parametrov toplivopodachi $v$ dizelyakh na rezhime puska], Nauka i tekhnika. № 1, pp. 40-47. 4. Polovinka E. M.. Garvalov R.Ya.. Mazur D.S.. Roznatovskiy A.O. (2018), "Research of starting modes of a marine high-speed Engine" [Issledovaniye puskovykh rezhimov sudovogo vysokooborotnogo Dvigatelya], Materials of the Science and Technology Conference "Richkoviy ta morskiy flot: ekspluatatsiya i remont», 22.03.2018 23.03.2018, Odesa. NU "OMA", pp 10-14. 5. Robustov V.V. (2006), "System analysis of the factors influencing the success of the ICE start-up in conditions of low negative temperatures" [Sistemnyy analiz faktorov vliyaniya na uspekh puska DVS v usloviyakh nizkikh otritsatelnykh temperatur], Omskiy nauchnyy vestnik, № 3 (36), pp. 100-104. 6. Markin A.G.. Zhuravskiy B.V.. Zhigadlo A.P. (2015), Power supply for starting an internal combustion engine of a car [Energoobespecheniye puska dvigatelya vnutrennego sgoraniya avtomobilya], Vestnik Sibirskoy gosudarstvennoy avtomobilnodorozhnoy akademii. № 5 (45), pp. 26-30. 7. Gritsyuk A. V. (2012), "Experience in applying the method of the planned experiment in the study of transient processes of starting a diesel engine" [Opyt primenneniya metoda planiruyemogo eksperimenta $v$ issledovaniyakh perekhodnykh protsessov puska dizelnogo dvigatelya], Dvigateli vnutrennego sgoraniya. № 2, pp. 53-59. 8. Nalimov V.V., Chernova N.A. (1967), "Statistical Methods for Planning Extreme Experiments" [Statisticheskive metody planirovaniya ekstremalnykh eksperimentov], Nauka, Moskow, 340 p. 9. Manzin M.Yu.. Zaikin A.A.. Roslov S.V.. Ivanov V.V. (2017), "On the issue of ensuring reliable starting of diesel engines at low temperatures" [K voprosu obespecheniya nadezhnogo puska dizelnykh dvigateley $v$ usloviyakh nizkikh temperatur], Vestnik Sibirskoy gosudarstvennoy avtomobilnoy akademii, № 3(55), pp. 88-94. 10. (1982), "Guidelines for the application of methods of mathematical experimental designe in students research, in course and diploma design" [Metodicheskie ukazaniya po primeneniyu metodov matematicheskogo planiirovaniya eksperimenta $v$ NIR studentov, $v$ kursovom i diplomnom proektirovanii], Harkovskij institut inzhenerov zhel.-dor. Transporta im. S.M. Kirova, Kharkiv, 34 p. 11. Andrukovich P. F., Golikova T.I., Kostina S.G. (1969), "Plans of the second order on a hypercube, close in properties to D-optimal" [Plany vtorogo poryadka na giperkube. blizkiye po svoystvam $k$ D-optimalnym l from book "New ideas about design of experience" [Novyye idei v planirovanii eksperimenta], Nauka, Moskow, pp. 140-153. 12. Antil Zh.. VaynbergAlle A. L. (2007), "D-optimal planning for polynomial regression: degree choice and robustness" [D-optimalnoye planirovaniye dlya polino-mialnoy regressii: vybor stepeni i robastnost], Prikladnaya ekonometrika, №. 4 (8), pp. 65-66. 13. Lapach S.N. (2016), "Robust Experiment Designs" [Robastnyye plany eksperimenta], Matematichni mashini i sistemi, № 4, pp. 111-121. 14. Brodskiy V.Z. Brodskiy L.I.. Brodskiy T.I.. Nalimova V.V. (1982), "Tables of experimental designs. For factorial and polynomial models. Reference edition" [Tablitsy planov eksperimenta. Dlya faktornykh i polinomialnykh modeley. Spravochnoye izdaniye], Metallurgiya, Moskow, $753 p$.

Надійшла до редакиії 18.06.2021 p.

Левченко Денис Вадимович - аспірант кафедри ДВЗ Харківського національного автомобільно-дорожнього університету, Харків, Україна, e-mail: denislev4enko@gmail.com/

\section{ВЫБОР И ОБОСНОВАНИЕ МАТЕМАТИЧЕСКОГО ПЛАНА 6-ТИ ФАКТОРНОГОЭКСПЕРИМЕНТА ПРИ ИССЛЕДОВАНИИ ПУСКОВЫХ КАЧЕСТВ ДВС}

\section{Д.В. Левченко}

Представлено практическое значение применения многофакторного регрессионного анализа в инженерной практике как необходимого шага на пути совершенствования и оптимизации сложных систем и процессов. Актуализированы цель и задачи оптимизации процесса пуска высокооборотного малолитражного дизеля. Представлены особенности подготовки многофакторного эксперимента исследуемого процесса на основе регрессионного анализа и теории математического планирования эксперимента. Определены качественные параметры для оптимизации процесса холодного пуска дизеля: мгновенное ускорение коленчатого вала $\mathrm{dn} / \mathrm{d} \tau$ в момент прокрутки внешним источники энергии, спустя время близкое к затраченному на пуск ДВС при оптимальных параметрах системы пуска и энергоемкость пуска, которая является интегральной характеристики эквивалента потрачено энергии во время прокрутки коленчатого вала внешним источники энергии. Исследовано влияние избранных 6-ти весомых факторов на предложенные параметры качества пуска дизеля. Обоснован выбор регрессионного уравнения в виде полного квадратичного полинома для воспроизведения исследуемых функций оценки качества процесса пуска, исходя из предшествующего изучения влияния некоторых отдельных факторов, использованных в исследовании. Проведен анализ предложений по выбору рационального плана шестифакторного эксперимента для поиска коэффициентов полинома регрессии второй степени. Дано обоснование решения относительно выбора плана, опираясь на требования экспериментального стенда и условий организации исследования, опыт предшественников и статистические критерии теории математического планирования экспериментов. Решение о выбранном план эксперимента в большей степени соответствует требованиям запланированного экспериментального исследования. Точки плана определены на многомерном кубе из необходимости варьирования на трех уровнях с равномерным шагом всех 6-ти факторов, которые были определены как влиятельные. В условиях имеющегося лабораторного стенда текущие значения факторов 
эквивалентной температуры холодного пуска, частоты прокрутки коленчатого вала и максимальной температуры свечей накаливания имеют вынужденную дисперсию установки в различных точках плана, а характер влияния факторов на показатель энергоемкости заблаговременно неизвестен. В качестве рационального плана эксперимента для организации текущего исследования выбран ортогональный центральный композиционный план Бокса-Уилсона, построенный за счет добавления к полнофакторному плану низшего порядка точек плана на осях факторного простора с сохранением требования ортогональности и симметричности плана.

Ключевые слова: Математическое планирование эксперимента; многофакторный эксперимент; квадратичный полином регрессии; центральный композиционный план.

\section{SELECTION AND JUSTIFICATION OF THE MATHEMATICAL 6 FACTORS EXPERIMENT PLAN IN THE STUDY OF ICE STARTING QUALITIES}

\section{D.V. Levchenko}

The practical significance of the application of multivariate regression analysis in engineering practice as a necessary step towards improving and optimizing complex systems and processes is presented. The goal and investigation tasks have been actualized to optimize the start-up process of a high-speed subcompact diesel engine. Preparation of the plural factors experiment features of diesel start-up process based on regression analysis and the theory of mathematical design of experiment are presented. Qualitative optimizing parameters of the diesel engine cold start are determined: instantaneous acceleration of the crankshaft $\mathrm{dn} / \mathrm{d} \tau$ at the time of crankshaft cranking by an external energy source close to the time spent on starting the engine with optimal parameters of the starting system and starting energy consumed during the crankshaft cranking by an external energy source. Six main factors influence on certain parameters of the diesel engine start quality have been investigated. The regression equation for assessing the quality of the start-up process is substantiated. The form of regression equation is a full quadratic polynomial for the reproduction of the investigated functions, based on the previous study of some used in the study individual factors influence. The analysis of proposals for rational plan selection of a six-factor experiment to find the coefficients of the second-degree regression polynomial is carried out. The substantiation of the decision regarding the choice of the plan is given. Selection was based on the requirements of the investigation test bench and the conditions for study organizing. Main impact had the predecessors experience of similar investigation and the statistical criteria for different plans of experiment comparison used in mathematical theory of design of experiments. The points of the plan have been defined on a multidimensional cube due to the need to vary on three levels with a uniform step of all 6 factors that were identified as influential. Under the conditions of the available laboratory test bench, the current values of the factors of equivalent cold start temperature, crankshaft-cranking speed and maximum temperature of the glow plugs have a variance of the installation at different points of the plan, and the nature of the factors on energy consumption is unknown in advance. As a rational experimental design for organizing the current study, the Box-Wilson orthogonal central compositional plan was chosen, built by adding plan points on the axes of the factorial space to the fullfactorial plan of the lowest order, while maintaining the requirement of orthogonality and symmetry of the plan.

Key words: mathematical design of experiment; plural factors experiment; quadratic regression polynomial; central compositional plan. 